\title{
Microstructures and Elevated Temperature Mechanical Properties of As-extruded ZM61-Sn Alloys
}

\author{
Tang Tian ${ }^{1,2}$, \\ Zhang Dingfei ${ }^{1,2}$, \\ Hu Guangshan ${ }^{1,2}$, \\ Xu Junyao ${ }^{1,2}$, \\ Pan Fusheng ${ }^{2,3}$ \\ ${ }^{1}$ College of Materials Science and Engineering, Chongqing University, Chongqing 400045, China; ${ }^{2}$ National Engineering Research Center for \\ Magnesium Alloys, Chongqing University, Chongqing 400044,China; ${ }^{3}$ Chongqing Academy of Science and Technology, Chongqing 401123, \\ China
}

\begin{abstract}
Microstructures, elevated temperature mechanical properties and fracture mechanisms of the as-extruded ZM61- $x \mathrm{Sn}(x=2,4$, 8, wt\%) alloys were investigated by optical microscope (OM), X-ray diffraction (XRD), scanning electron microscope (SEM) and high temperature tensile tests. The results reveal that the addition of Sn can refine microstructures and the refinement effect increases with the increase of Sn content. The average grain sizes of the as-extruded ZM61- $x \operatorname{Sn}(x=2,4,8)$ alloys are 11,8 and $4 \mu \mathrm{m}$, respectively. With the increasing of Sn amount, the strength of experimental alloys increases at first and decreases afterward. ZM61-4Sn alloy shows the highest strength, whose ultimate tensile strength and yield strength are 216 and $173 \mathrm{MPa}$ tested at $180{ }^{\circ} \mathrm{C}$, respectively. The ductility increases with the content of Sn increasing, and the elongation of as-extruded ZM61- $x \mathrm{Sn}(x=2,4,8)$ alloys are $183.8 \%, 235.8 \%$ and $258.6 \%$, respectively, when tensile temperature reaches $300{ }^{\circ} \mathrm{C}$. The ZM61-4Sn alloy has the optimal coalescence of strength and ductility. The localized necking leads to the final fracture of the specimens and the micro-void coalescence is the main fracture mechanism. Incomplete dynamic recrystallization occurs when tensile tests are carried out at 260 and $300{ }^{\circ} \mathrm{C}$.
\end{abstract}

Key words: ZM61-Sn alloy; extrusion; microstructure; elevated temperature mechanical properties

As the lightest structural metallic materials, magnesium $(\mathrm{Mg})$ alloys exhibit great potential applications in automobile and aerospace for decreasing the mass of vehicles and improving fuel consumption ${ }^{[1-3]}$. However, poor mechanical properties at elevated temperatures restrict their further applications in some high temperature parts (such as engine $\left.{ }^{[4,5]}\right)$. Therefore, the development of new heat resistant Mg alloys with excellent mechanical properties is essential. Previous investigations have revealed that alloying is an effective method to improve the elevated temperature mechanical properties of $\mathrm{Mg}$ alloys and the rare earth elements (RE) such as $\mathrm{Nd}, \mathrm{Y}, \mathrm{Ce}$ are commonly used $^{[6-8]}$. However, the high cost of rare earth elements restricts their wide applications. It is necessary to develop promising $\mathrm{Mg}$ alloys with good elevated temperature mechanical properties and without RE elements.
According to the $\mathrm{Mg}$-Sn binary phase diagram, the maximum solid solubility of $\mathrm{Sn}$ is $14.85 \mathrm{wt} \%$, and its eutectoid temperature is $561{ }^{\circ} \mathrm{C}$ which is similar to those of some rare earth elements ${ }^{[9]}$. Some studies have reported that the addition of Sn element can effectively refine gains, form high melting, high hardness and good thermally stable $\mathrm{Mg}_{2} \mathrm{Sn}$ intermetallics in $\mathrm{Mg}$ alloys ${ }^{[10,11]}$. Consequently, $\mathrm{Sn}$ element has a huge potential to replace the RE element to enhance the elevated temperature properties of $\mathrm{Mg}$ alloys ${ }^{[12]}$ $\mathrm{Chen}^{[13]}$ et al have found that the added $0.5 \mathrm{wt} \% \mathrm{Sn}$ into ZA62 alloys can enhance their heat resistance owing to the fine $\mathrm{Mg}_{2} \mathrm{Sn}$ phase disperse in matrix.

Compared with cast $\mathrm{Mg}$ alloys, wrought $\mathrm{Mg}$ alloys have better mechanical properties. As a new high strength wrought Mg alloys, ZM61 has a wide application due to its relatively low price. The effects of $\mathrm{Sn}$ element on the mi-

\section{Received date: August 20, 2016}

Foundation item: National Great Theoretic Research Project (2013CB632200); National Natural Science Foundation of China (51474043); Chongqing Municipal Government Project (CSTC2013JCYJC60001); Education Commission of Chongqing Municipality (KJZH14101); Sharing Fund of Chongqing University's Large-scale Equipment

Corresponding author: Zhang Dingfei, Ph. D., Professor, College of Materials Science and Engineering, Chongqing University, Chongqing 400045, P. R. China, Tel: 0086-23-65112491, E-mail: zhangdingfei@cqu.edu.cn 
crostructure and room temperature strength in ZM61 have been investigated, but its elevated temperature performance is not involved. In the present paper, $\mathrm{Sn}$ element was added into the ZM61 Mg alloy for high-temperature tensile experiments, to investigate the microstructures and elevated temperature mechanical properties of the as-extruded Mg-Zn-Mn-Sn alloys.

\section{Experiment}

Commercial high purity $\mathrm{Mg}$ (>99.9\%), Zn (>99.9\%), Sn (>99.9\%) and $\mathrm{Mg}-4.1 \mathrm{Mn}$ (wt\%) master alloys were used to prepare the experimental alloys. These alloys were heated to about $720{ }^{\circ} \mathrm{C}$ in an electrical resistance furnace under $\mathrm{Ar}$ protecting atmosphere. The chemical composition of the experimental alloys is listed in Table 1 . Then the castings were homogenized at $330{ }^{\circ} \mathrm{C}$ for $15 \mathrm{~h}$ and $420{ }^{\circ} \mathrm{C}$ for $2 \mathrm{~h}$ directly followed by water quenching. The homogenized alloys were extruded to bars of $16 \mathrm{~mm}$ in diameter at $350{ }^{\circ} \mathrm{C}$ with the extrusion rate of $1 \sim 2 \mathrm{~m} / \mathrm{min}$ and extrusion ratio of 25 . The extruded bars were machined to be tensile test specimens with $25 \mathrm{~mm}$ in gauge length and $5 \mathrm{~mm}$ in diameter. The tensile tests were carried out in CMT-5105 stretcher at a speed of $3 \mathrm{~mm} / \mathrm{min}$ at four different temperatures $\left(180,220,260\right.$ and $\left.300{ }^{\circ} \mathrm{C}\right)$. The specimens were first heated to the deformation temperature at the rate of $20{ }^{\circ} \mathrm{C} /$ $\mathrm{min}$, and then held for $8 \mathrm{~min}$ to guarantee isothermally. The tensile directions were parallel to the extrusion direction. In each condition three specimens were used to ensure the data's reproducibility.

The chemical composition was analyzed by a XRF-1800 CCDE sequential X-ray fluorescence spectrometer. Phase components were characterized by a Rigaku D/max 2500 PC X-ray diffractometer using $\mathrm{Cu}-\mathrm{K} \alpha$. The optical microstructures of specimens were photographed by a LEXT 2000 laser metallographic microscope. The specimens for microstructure observation were ground and etched by acetic-picral etchant $(7 \mathrm{~mL}$ ethanol, $1 \mathrm{~mL}$ acetic acid and $5 \mathrm{~g}$ picric acid). Fractured surface morphologies were observed by TESCAN VEGA II scanning electron microscope equipped with an INCA Energy 350 energy dispersive $\mathrm{X}$-ray spectrometer (EDS).

\section{Results and Discussion}

\subsection{Microstructures of as-extruded ZM61-Sn alloys}

Fig. 1 shows the XRD patterns of as-extruded ZM61 and ZM61- $x$ Sn $(x=2,4,8, \mathrm{wt} \%)$ alloys. Besides $\alpha$-Mg matrix, four kinds of second phase are detected in the ZM61-Sn

Table 1 Chemical composition of ZM61- $x$ Sn alloys (wt\%)

\begin{tabular}{ccccc}
\hline Alloy & $\mathrm{Mg}$ & $\mathrm{Zn}$ & $\mathrm{Mn}$ & $\mathrm{Sn}$ \\
\hline ZM61-2Sn & 91.11 & 6.15 & 0.96 & 1.78 \\
ZM61-4Sn & 88.82 & 6.17 & 0.85 & 4.16 \\
ZM61-8Sn & 85.13 & 5.88 & 0.94 & 8.05 \\
\hline
\end{tabular}

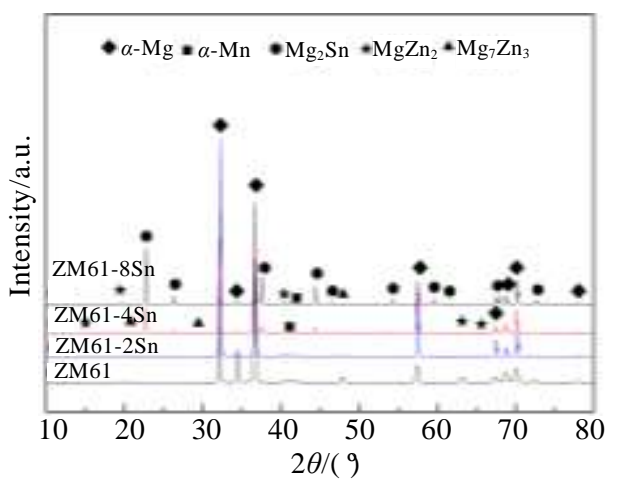

Fig.1 XRD patterns of as-extruded ZM61 and ZM61-xSn alloys

alloys. With the addition of Sn element, a new $\mathrm{Mg}_{2} \mathrm{Sn}$ phase forms ${ }^{[14]}$. The phase composition of ZM61-Sn alloys is $\alpha-\mathrm{Mg}, \alpha-\mathrm{Mn}, \mathrm{Mg}_{2} \mathrm{Sn}, \mathrm{MgZn}_{2}$ and $\mathrm{Mg}_{7} \mathrm{Zn}_{3}$ phases.

Fig. 2 shows the microstructures in longitudinal extrusion of as-extruded ZM61- $x \mathrm{Sn}$ alloys. The fine equiaxed grains in the longitudinal direction suggest that dynamic recrystallization (DRX) occurs during extrusion at $350{ }^{\circ} \mathrm{C}$. The dimension of extrusion streamlines which consist of fragmentized second phase increases with the Sn content increasing. Some extremely fine grains exist surrounding the extrusion streamlines which indicates that the irregular fragmentized compounds restrain the recrystallized grains growth during the hot extrusion process. The grain sizes decrease gradually with the increase of Sn content and the average values measured by linear intercept are 11,8 and $4 \mu \mathrm{m}$, respectively.

The SEM images of the experimental alloys are shown in Fig.3. The extrusion streamlines are principally constituted of $\mathrm{Mg}_{2} \mathrm{Sn}$ and $\mathrm{Mg}-\mathrm{Zn}$ compounds through the EDS analysis (Table 2). A small number of $\mathrm{Mg}_{2} \mathrm{Sn}$ particles can be found in ZM61-2Sn alloy, but the volume fraction remarkably balloons in ZM61-8Sn alloy, and the dimension of $\mathrm{Mg}_{2} \mathrm{Sn}$ particles aggrandizes with the increase of Sn content, because the undissolved $\mathrm{Mg}_{2} \mathrm{Sn}$ phases are squeezed to fragments during the extrusion, and these fragments distribute along with the longitudinally extruded direction in the form of stringers. In addition, some relatively fine particles distribute in the Mg matrix. They are formed by dynamic precipitation during the extrusion process ${ }^{[15]}$.

\subsection{Mechanical properties at elevated temperatures}

Fig. 4 shows the engineering stress and strain curves of the specimens at different tensile temperatures. The engineering stress and strain curves can be divided into four stages, elastic deformation, plastic deformation, localized necking and fracture. The flow stress increases to the peak value first, and then decreases as the strain increases, until to fracture. A rapid decrease in the flow stress can be ob- 

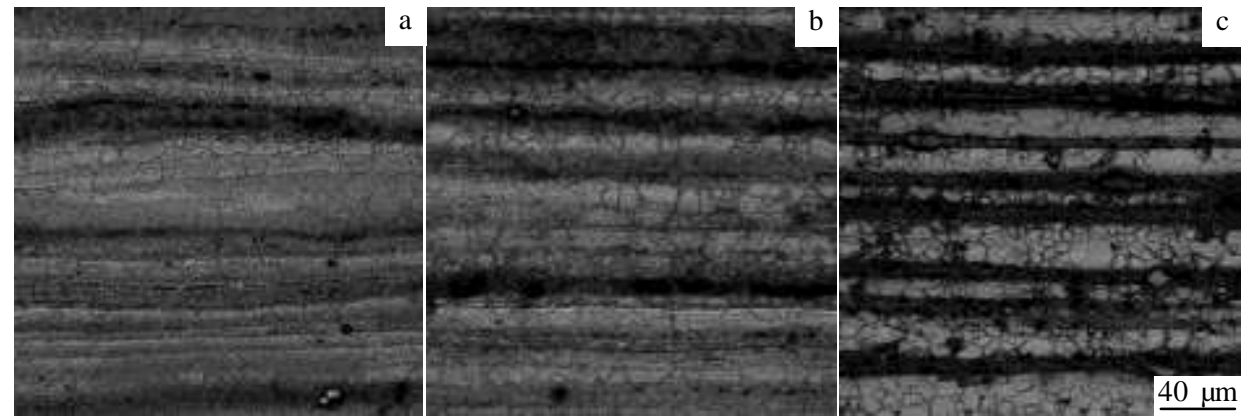

Fig.2 Optical images of ZM61-xSn alloys: (a) ZM61-2Sn, (b) ZM61-4Sn, and (c) ZM61-8Sn

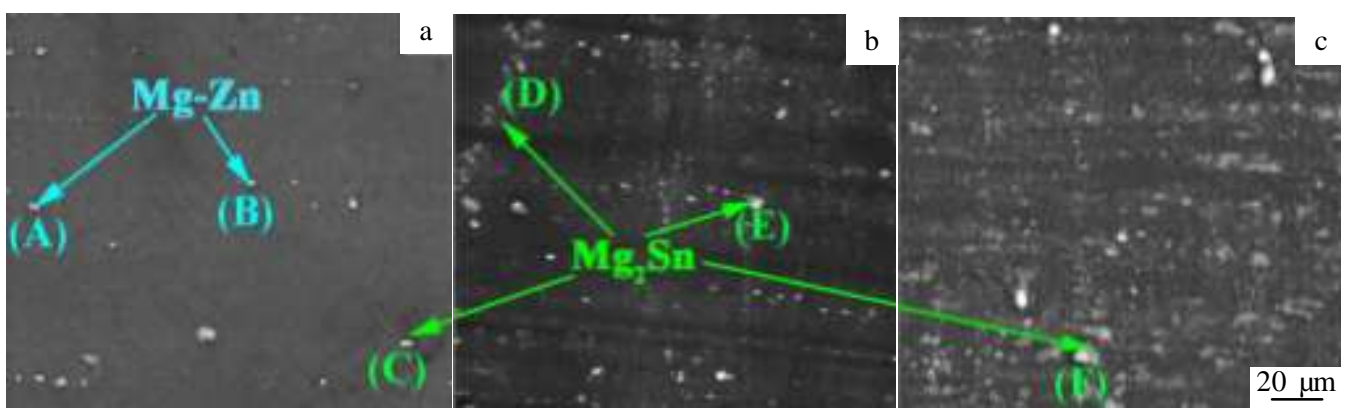

Fig.3 SEM images of ZM61- $x$ Sn alloys: (a) ZM61-2Sn, (b) ZM61-4Sn, and (c) ZM61-8Sn

Table 2 EDS results of the points indicated in Fig.3

\begin{tabular}{ccccc}
\hline \multirow{2}{*}{ Point } & \multicolumn{3}{c}{ Element/at\% } & \multirow{2}{*}{ Phase } \\
\cline { 2 - 4 } & $\mathrm{Mg}$ & $\mathrm{Zn}$ & $\mathrm{Sn}$ & \\
\hline A & 35.81 & 64.19 & - & $\mathrm{MgZn}_{2}$ \\
B & 76.61 & 23.39 & - & $\mathrm{Mg}_{7} \mathrm{Zn}_{3}$ \\
C & 64.49 & - & 35.51 & $\mathrm{Mg}_{2} \mathrm{Sn}$ \\
D & 65.24 & - & 34.76 & $\mathrm{Mg}_{2} \mathrm{Sn}$ \\
E & 63.62 & - & 36.38 & $\mathrm{Mg}_{2} \mathrm{Sn}$ \\
F & 67.85 & - & 32.15 & $\mathrm{Mg}_{2} \mathrm{Sn}$ \\
\hline
\end{tabular}

served when the tensile test were implemented at $180 \sim 260{ }^{\circ} \mathrm{C}$, and the rate of decreasing increases with the $\mathrm{Sn}$ amounts increase. The stress and strain curves have a steady state in the ZM61-4Sn and ZM61-8Sn alloys when the deformation is at $300{ }^{\circ} \mathrm{C}$. Dislocations multiply remarkably at the beginning of deformation, leading to the work harden and enhancing the strength of alloy, so the flow stress increases at the initial deformation stage. With the strain increasing dynamic recovery and DRX occur in Mg alloy, leading materials soften, and flow stress gradually declines. Steady state of the stress and strain curves indicates that the work hardening and softening process achieve a dynamical balance ${ }^{[16,17]}$.

Fig.5 shows the tensile properties of the as-extruded ZM61- $x$ Sn alloys at different temperatures. The strength and elongation (EL) of alloys are affected by the tension temperature and Sn content. The strength decreases and the
EL increases with the increase of deformation temperature. When tension tests are carried out at $180{ }^{\circ} \mathrm{C}$, the EL of the specimens are $70.7 \%, 59.5 \%, 80.9 \%$, and the yield strength (YS) are 158, 173, $147 \mathrm{MPa}$, respectively. When the deformation temperature reaches to $300{ }^{\circ} \mathrm{C}$, the $\mathrm{EL}$ of the specimens are $183.8 \%, 235.8 \%, 258.6 \%$, and the YS are 47, 63, $56 \mathrm{MPa}$, respectively. The dominant deformation mechanisms for $\mathrm{Mg}$ alloys at room temperature are the basal slip and twinning. With the temperature increasing, non-basal slip system can be activated. Therefore, the ductility of $\mathrm{Mg}$ alloys increases with the deformation temperature increasing ${ }^{[18]}$. The main deformation mechanisms are non-basal dislocation slip and climb at elevated temperature; as a result dynamical recovery and DRX weaken the alloy strength. Therefore, the strength decreases rapidly with the temperature increases.

The strength increases first and then decreases with the increase of Sn. The ZM61-4Sn alloy has the highest ultimate tensile strength (UTS) and YS. The EL increases as the $\mathrm{Sn}$ content increases constantly. In conclusion, the alloy with the addition of $4 \%$ Sn shows the best coalescence of strength and ductility among the test alloys. The UTS, YS and EL of ZM61-4Sn alloy are $216 \mathrm{MPa}, 173 \mathrm{MPa}$ and $59.5 \%$ when tensile tested at $180{ }^{\circ} \mathrm{C}$.

The improvement of tensile strength of the experimental alloys can be mainly ascribed to three aspects: (1) the addition of Sn refines the microstructure. According to Hall- 

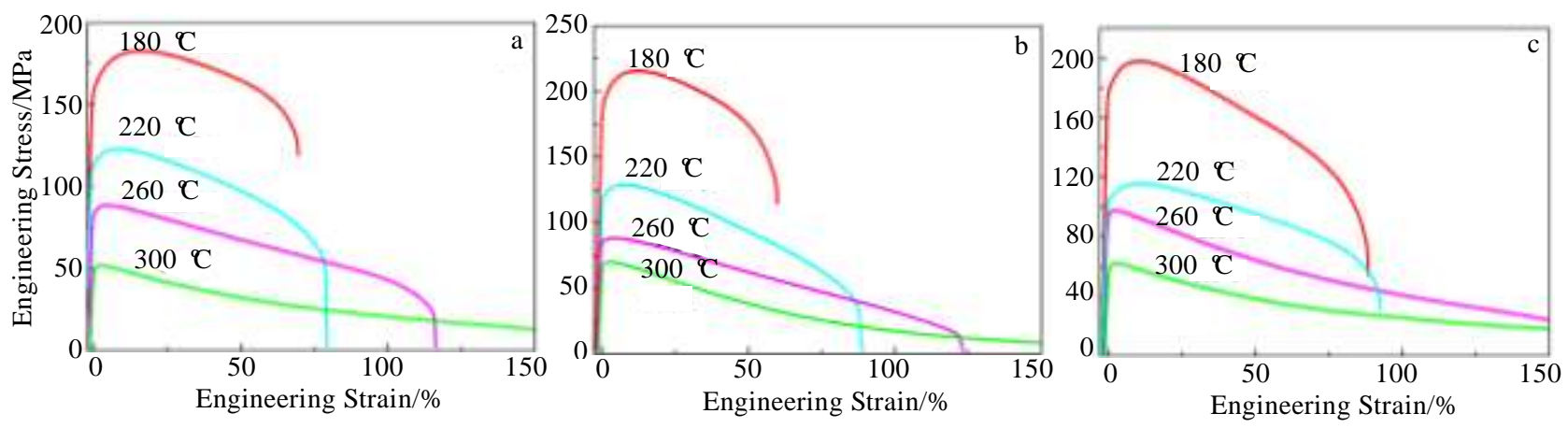

Fig.4 Engineering stress-strain curves of ZM61-xSn alloys tested at different temperatures: (a) ZM61-2Sn, (b) ZM61-4Sn, and (c) ZM61-8Sn
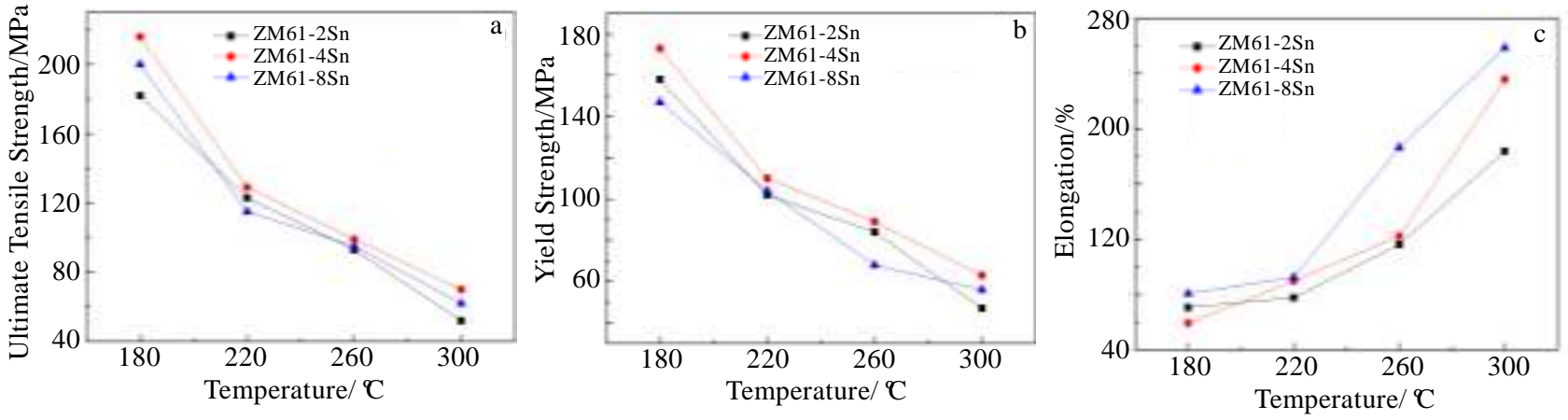

Fig.5 Tensile properties of ZM61- $x$ Sn alloys tested at different temperatures: (a) UTS, (b) YS, and (c) EL

Petch relationship $\left(\sigma=\sigma_{\mathrm{o}}+k d^{-1 / 2} . \sigma\right.$ is yield strength, $d$ is average grain size, $\sigma_{\mathrm{o}}$ and $k$ are constants for the given alloys), the decrease of grain size can greatly enhance the tensile strength of alloys ${ }^{[19]}$. (2) $\mathrm{Mg}$ atoms in matrix replaced by $\mathrm{Sn}$ and $\mathrm{Zn}$ atoms would lead to lattice distortions, hinder the motion of dislocation and improve the strength of the alloys. (3) The discrete $\mathrm{Mg}_{2} \mathrm{Sn}$ particles distributed in grains and boundaries can effectively impede dislocation motion and grain boundary sliding, which increases the strength. However, with the $\mathrm{Sn}$ content increasing, the dimension of the $\mathrm{Mg}_{2} \mathrm{Sn}$ phases increases obviously. These coarse $\mathrm{Mg}_{2} \mathrm{Sn}$ phases deteriorate the continuity of $\mathrm{Mg}$ matrix, which may act as crack initiation. Therefore, the amount of $\mathrm{Sn}$ addition in ZM61 alloys should be limited in a certain range.

\subsection{Fracture mechanisms}

Fig.6 shows the macroscopical image of the fracture specimens tested at different temperatures. The specimens deformation in the gauge segment is quite uniform, and when the deformation temperature is over $260{ }^{\circ} \mathrm{C}$, the specimens exhibit diffuse necking characteristics, which indicates the appearance of $\mathrm{DRX}^{[20]}$. An obvious localized necking region can be observed when the deformation are at 260 and $300{ }^{\circ} \mathrm{C}$. The connection strength of the localized necking region can't bear the applied load, leading to the fracture of the specimens.

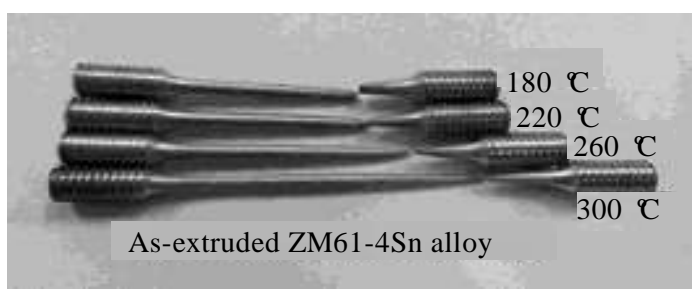

Fig.6 Macroscopical image of the fracture specimens tested at different temperatures

Fig.7 shows the fracture morphologies of ZM61-4Sn alloys tested at different temperatures. In Fig. $7 \mathrm{a}$ and $7 \mathrm{~b}$, the fracture surfaces are composed of a large number of fine dimples. With the tensile temperature increasing, in Fig.7c and $7 \mathrm{~d}$, the fracture surfaces are composed of big cavitations, which means micro-void coalescence is the main fracture mechanism. Localized necking is hard to appear at relatively low deformation temperature, so it is likely to form small and shallow dimples. With the increasing of deformation temperature, the material transfer and diffusion ability increase, and these small dimples tend to coalesce to be cavitations ${ }^{[21]}$. The characters of recrystallized grains can also be observed in Fig.7c and 7d. 

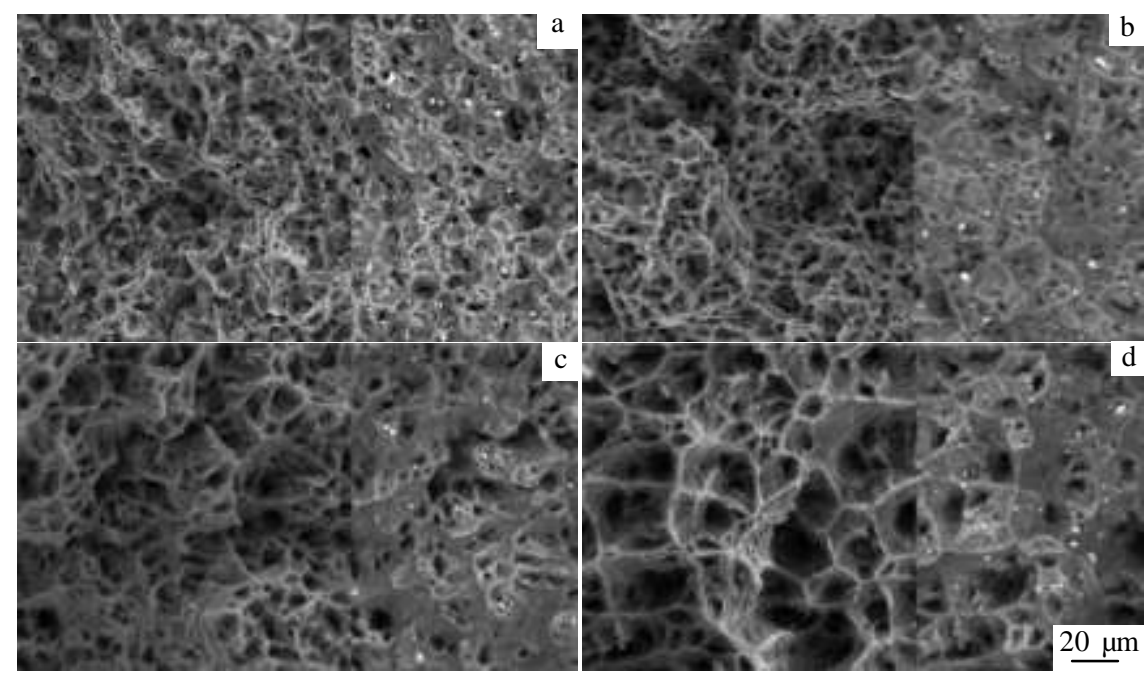

Fig.7 SEM and BSE images of fracture surface of ZM61-4Sn alloys tested at different temperatures: (a) $180{ }^{\circ} \mathrm{C}$, (b) $220{ }^{\circ} \mathrm{C}$, (c) $260{ }^{\circ} \mathrm{C}$, and (d) $300{ }^{\circ} \mathrm{C}$

Fig. 8 shows the optical images of the longitudinal section near the fracture surface of the ZM61-4Sn alloys tested at different temperatures. Obviously, the temperature has a significant effect on the microstructures. When the deformation temperature is below $220{ }^{\circ} \mathrm{C}$, the specimens have no obvious transformation compared with the original organization. However, when the tensile temperature reaches $260{ }^{\circ} \mathrm{C}$, the microstructures change inhomogeneous, the fine DRX grains occur in the grain boundaries, as shown in Fig.8c. The volume fraction of DRX grains is increased with the temperature increasing, as shown in Fig.8d.

$\mathrm{Mg}$ alloy is a typical material with low stacking fault energy ${ }^{[22,23]}$. The limit of cross slip and climb of edge dislocation is likely to cause DRX in Mg alloys ${ }^{[24]}$. In addition, the grain boundaries can hinder the motion of dislocation, and a great number of dislocation accumulate around the grain boundaries during the plastic deformation, which promotes the nucleation of DRX at the grain boundaries.

The relatively low deformation temperature can't provide enough energy for the dislocation to free motion, so there is no obvious DRX grains appearing in Fig.8a and 8b. The ability of dislocation movement increases with the increase of temperature, and the dislocation density is higher on account of the high deformation temperature, which would promote the germination of DRX. Consequently, incomplete DRX structures are clearly presented at the deformation temperature of 260 and $300{ }^{\circ} \mathrm{C}$.

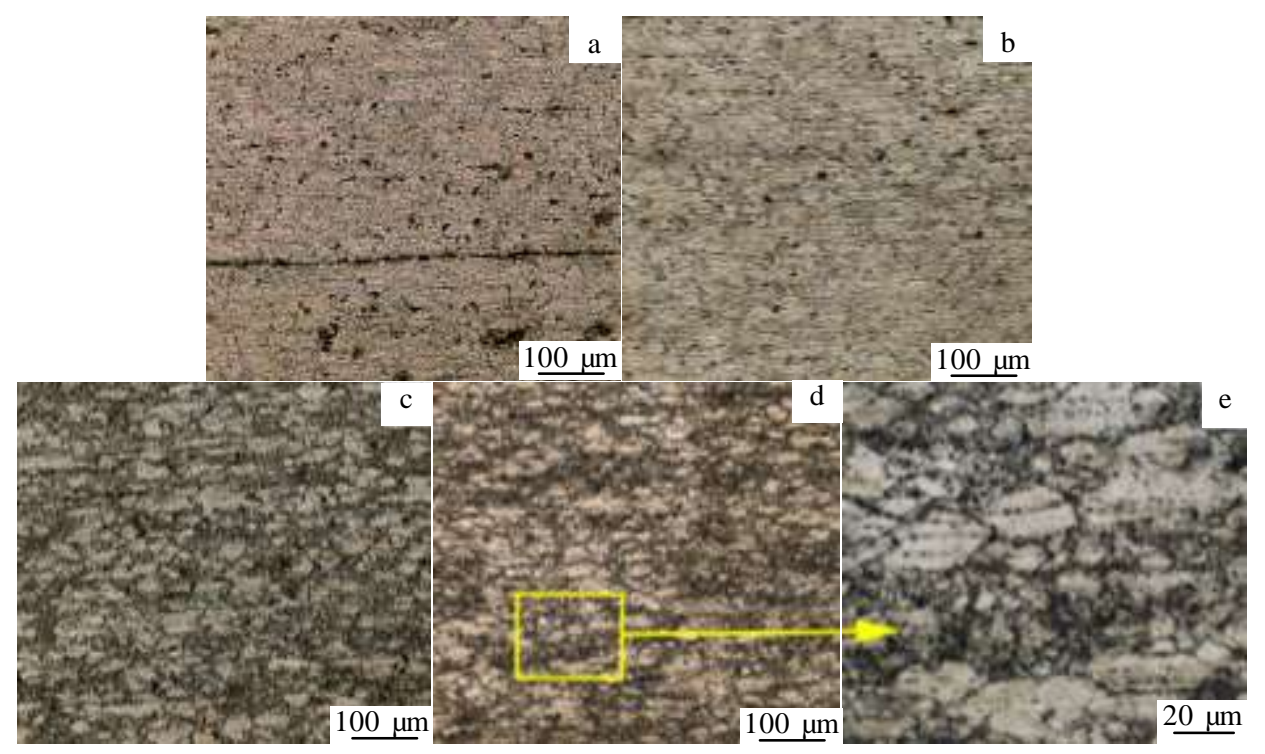

Fig.8 Optical images from longitudinal sections adjacent fracture surface of ZM61-4Sn alloys tested at different temperatures: (a) $180{ }^{\circ} \mathrm{C}$, (b) $220{ }^{\circ} \mathrm{C}$, (c) $260{ }^{\circ} \mathrm{C}$, and (d, e) $300{ }^{\circ} \mathrm{C}$ 


\section{Conclusions}

1) The phase composition of ZM61- $x \operatorname{Sn}(x=2,4,8$, wt $\%)$ alloys is $\alpha-\mathrm{Mg}, \alpha-\mathrm{Mn}, \mathrm{Mg}_{7} \mathrm{Zn}_{3}, \mathrm{Mg}_{2} \mathrm{Sn}$ and $\mathrm{MgZn}_{2}$ phases. The addition of $\mathrm{Sn}$ element can remarkably refine the microstructure, and the average grain size are 11,8 and $4 \mu \mathrm{m}$, respectively.

2) The strength increases first and then decreases with the increase of $\mathrm{Sn}$, and the elongation increases constantly with the increase of Sn. The ZM61-4Sn alloy has the optimal coalescence of strength and ductility, and the UTS, YS and EL are $216 \mathrm{MPa}, 173 \mathrm{MPa}$ and $59.5 \%$, respectively, when tensile temperature is $180{ }^{\circ} \mathrm{C}$.

3) The localized necking leads to the final fracture of the specimens and the main fracture mechanism is micro-void coalescence. Incomplete DRX occurs when deformation temperature is over than $260{ }^{\circ} \mathrm{C}$.

\section{References}

1 Yin D D, Wang Q D, Boehlert C J et al. Materials Science and Engineering $A[\mathrm{~J}], 2012,546: 239$

2 Chen C J, Wang Q D, Yin D D. Journal of Alloys and Compounds[J], 2009, 487(1-2): 560

3 Zhang Guanghao, Chen Jihua, Yan Hongge et al. Journal of Alloys and Compounds[J], 2014, 592: 250

4 Sha G, Li J H, Xu W et al. Materials Science and Engineering $A[\mathrm{~J}], 2010,527(20): 5092$

5 Zhang Jinghuai, Xu Longjiang, Jiao Yufeng et al. Materials Science and Engineering A[J], 2014, 610: 139

6 Cheng W L, Park S S, Tang W N et al. Journal of Rare Earths[J], 2010, 28(5): 785

7 Stefano Spigarelli, Mohamad El Mehtedi. Scripta Materialia[J], 2010, 63(7): 704

8 Zhang Xiaolong, Wang Zhaohui, Du Wenbo et al. Materials and Design[J], 2014, 58: 277

9 Kim Y K, Kim Do H, Kim W T et al. Materials Letters $[\mathrm{J}]$, 2013, 113: 50

10 Hasani G H, Mahmudi R. Materials and Design[J], 2011, 32(7): 3736

11 Dong Xuguang, Fu Junwei, Wang Jing et al. Materials and Design[J], 2013, 51: 567

12 Ghosh P, Mezbahul-Islam M, Medraj M. Calphad[J], 2012, 36: 28

13 Chen Jihua, Chen Zhenhua, Yan Hongge et al. Journal of Alloys and Compounds[J], 2008, 461(1-2): 209

14 Qi Fugang, Zhang Dingfei, Zhang Xiaohua et al. Journal of Alloys and Compounds[J], 2014, 585: 656

15 Cheng W L, Park S S, You B S et al. Materials Science and Engineering $A[\mathrm{~J}], 2010,527(18-19): 4650$

16 Wei Shanghai, Zhu Tianping, Michael Hodgson et al. Materials Science and Engineering A[J], 2013, 585: 139

17 Tang Y Q, Chen Y G, Xiao S F et al. Rare Metal Materials and Engineering [J], 2014, 43(6): 1291

18 Jäger A, Lukáč $\mathrm{P}$, Gärtnerová V et al. Journal of Alloys and Compounds[J], 2004, 378(1-2): 184

19 Wang Jianli, Yang Jie, Wu Yaoming et al. Materials Science and Engineering $A[\mathrm{~J}], 2008,472(1-2): 332$

20 Deng J, Lin Y C, Li S S et al. Materials and Design[J], 2013, 49: 209

21 Toda Hiroyuki, Shamsudin Zul Azri Bin, Shimizu Kazuyuki et al. Acta Materialia[J], 2013, 61(7): 2403

22 Zhou M, Lin Y C, Deng J et al. Materials and Design[J], 2014, 59: 141

23 Lin Y C, Deng J, Jiang Y Q et al. Materials and Design $[\mathrm{J}]$, 2014, 55: 949

24 Shi Baoliang, Luo Tianjiao, Wang Jing et al. Transactions of Nonferrous Metals Society of China[J], 2013, 23(9): 2560

\title{
挤压态 ZM61-Sn 合金的显微组织及高温力学性能
}

\author{
唐 甜 ${ }^{1,2}$, 张丁非 ${ }^{1,2}$, 胡光山 ${ }^{1,2}$, 胥钧耀 ${ }^{1,2}$, 潘复生 ${ }^{2,3}$ \\ (1. 重庆大学 材料科学与工程学院, 重庆 400045) \\ (2. 重庆大学 国家镁合金材料工程技术研究中心, 重庆 400044) \\ (3. 重庆市科学技术研究院, 重庆 401123)
}

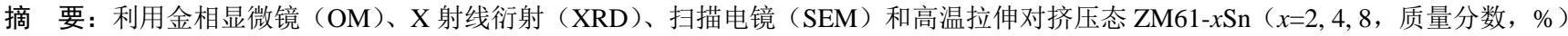
合金的显微组织、高温力学性能和断裂机制进行了研究。结果表明添加 $\mathrm{Sn}$ 元素可有效细化合金组织且细化效果随 $\mathrm{Sn}$ 含量的增加而 增强。挤压态 ZM61- $x \operatorname{Sn}(x=2,4,8)$ 合金的平均晶粒尺寸分别为 11,8 和 $4 \mu \mathrm{m}$ 。随 $\mathrm{Sn}$ 含量的增加, 合金的力学性能先升高后降低。 在所有的实验合金中 ZM61-4Sn 合金的强度最高, 当在 $180{ }^{\circ} \mathrm{C}$ 下进行拉伸实验时, 其极限抗拉强度和屈服强度分别为 216 和 $173 \mathrm{MPa}$ 。 合金的延伸率随 $\mathrm{Sn}$ 含量的增加而增加, 当拉伸温度为 $300{ }^{\circ} \mathrm{C}$ 时, ZM61- $x \mathrm{Sn}(x=2,4,8)$ 合金的延伸率分别为 $183.8 \%, 235.8 \%$ 和 $258.6 \%$ 。 ZM61-4Sn 合金具有最好的强度和塑性的结合。试样最后的断裂主要由局部缩颈引起以及试样的主要断裂机制为显微孔洞聚集。当在 260 和 $300{ }^{\circ} \mathrm{C}$ 下拉伸时, 合金发生了不完全的动态再结晶。
\end{abstract} 关键词: ZM61-Sn 合金; 挤压; 显微组织; 高温力学性能 